\title{
Extending primary care: potential learning from Italy
}

\author{
Sara E. Shaw ${ }^{1}$ and Geoffrey Meads ${ }^{2}$ \\ ${ }^{1}$ Senior Lecturer in Health Policy Research, Global Health, Innovation and Policy Unit, Centre for Primary Care and \\ Public Health, Queen Mary University of London, London, UK \\ ${ }^{2}$ Honorary Professor of International Health Studies, Warwick Medical and Winchester Business Schools, UK
}

\begin{abstract}
Health systems across Europe are under increasing pressure to shift care outside hospitals and into community settings. The emphasis is on providing high-quality, coordinated care for a growing population of older patients and those with long-term conditions. Extended primary care is regarded as the key means of achieving such a shift. We report learning following exploratory visits to two sites in Italy, each providing an example of a primary care organisation with extended general practices, community health and local resource utilisation responsibilities. We draw out three areas of potential interest - shifting care from hospital to community settings, facilitating localism and enabling stable leadership - all of which appear to provide a means for local clinicians, managers and their communities to commission care according to local needs. We conclude by recommending that primary care researchers consider undertaking further work in Italy, building on this exploratory work and more systematically exploring the effects of such programmes.
\end{abstract}

Key words: exploratory visits; extended primary care; Italy

Received 25 July 2011; revised 3 January 2012; accepted 11 January 2012;

first published online 14 February 2012

\section{Background}

Across Europe, increased attention is being given to extending primary care (Atun, 2004; Health Council of the Netherlands, 2004; Saltman et al., 2006; Meads, 2009). The aim is to address a growing older population and rising incidence of long-term conditions by shifting care from hospital- to community-based settings (Smith and Ovenden, 2007). The vision is one where services are more efficient and responsive, incorporate a coordinated and multidisciplinary approach to delivering high-quality care and connect firmly with the needs of service users by enabling a growth in the activities devolved to primary care.

Correspondence to: Dr Sara E. Shaw, Global Health, Innovation and Policy Unit, Centre for Primary Care and Public Health, Queen Mary University of London, Yvonne Carter Building, 58 Turner Street, London E1 2AB, UK. Email: s.shaw@qmul.ac.uk

(C) Cambridge University Press 2012
Primary care professionals are thought to be well placed to manage demand, provide personalised services, advance quality and use resources efficiently. However, questions remain about whether primary care is capable of taking on the leadership of running a whole healthcare system.

Little attention has been paid to extended primary care in Italy, where the decision to devolve national powers to regions with their own highly decentralised structures has led to rapid, if variable, development. We therefore report from exploratory visits to two Italian sites (see Box 1): each in a region with extended primary care at the heart of its healthcare strategy. Our paper is intended as an opinion piece, highlighting areas of potential learning for primary care researchers drawn from our site visits, each of which involved a mix of informal interviews and documentary review. 


\section{Strategic development of health care in Italy}

Like most other European countries, the Italian National Health System (Servizio Sanitario Nazioanale) offers universal healthcare coverage backed by the state. Primary care is largely provided by GPs and paediatricians who are independent contractors acting as gatekeepers to secondary care.

National reforms have promoted cooperation amongst healthcare and social care providers and an integrated framework for delivering care to targeted groups (Donatini et al., 2001). In addition, there has been a steady decentralising of power to 20 regions, each having a directly elected government with wide legislative and administrative powers (Maio and Manzoli, 2002). Healthcare strategy is therefore largely devolved to the regions with many remaining committed to public provision (Lombardy being a notable exception, see eg, Stancati, 2010). In each region, local healthcare executives undertake populationbased health management and purchasing at the locality level.

In the regions we visited - Tuscany and Emilia Romagna - regional reforms focussed explicitly on extended primary care. In both regions, the term is understood as a concept that embraces both individual and population health requirements and as a service provided from directly accessed, frontline units. In Tuscany, the emphasis is on a coordinating health and social care, implementing the Chronic Care Model (Wagner et al., 1996) across group practices, combining budgets and aligning both managerial and financial structures. At the locality level, six new 'Health Homes' have been jointly commissioned with the aim of reducing acute hospital usage and costs. St. Andrea's Health Home was the first to emerge and with a focus on health and social care integration (Box 2).

In Emilia Romagna, the emphasis is on increasing the primary care budget and decreasing hospital admissions through shared medical care. The Max Ivan Chercish Polyambulatoria is a group general practice in Bologna (Box 3) that has been driving vertical integration with secondary care. Shared care across GPs and specialists is facilitated by locally adapted national guidelines. The quality of clinical relationships and the lack of professional boundaries appear to be the key to developing and maintaining highquality services out of hospital.

\section{Shifting care from hospital to community settings}

Since its opening in 2008, St. Andrea's has steadily increased its patient registrations while simultaneously reducing hospital referrals and inpatient admissions (now 140 per 1000 patients). This has been achieved by expanding the activities

\section{Box 1 Overview of case study sites}

\begin{tabular}{lllll}
\hline Case study & $\begin{array}{l}\text { Approach to } \\
\text { extending primary } \\
\text { care }\end{array}$ & $\begin{array}{l}\text { Organisational } \\
\text { model }\end{array}$ & $\begin{array}{l}\text { Registered } \\
\text { population }\end{array}$ & Service focus \\
\hline $\begin{array}{l}\text { Max Ivan Chercish } \\
\begin{array}{l}\text { Polyambulatoria; } \\
\text { Bologna, Emilia }\end{array}\end{array}$ & $\begin{array}{l}\text { Shared medical care } \\
\text { across GPs and } \\
\text { specialists }\end{array}$ & $\begin{array}{l}\text { Group general } \\
\text { practice }\end{array}$ & 7100 & $\begin{array}{l}\text { Registered } \\
\text { patient list }\end{array}$ \\
$\begin{array}{l}\text { Sant' Andrea } \\
\begin{array}{l}\text { Health Home; } \\
\text { Empoli, Tuscany }\end{array}\end{array}$ & $\begin{array}{l}\text { Coordinated health } \\
\text { and social care } \\
\text { focussed on reducing } \\
\text { acute hospital usage }\end{array}$ & $\begin{array}{l}\text { Health Home/ } \\
\text { cooperative }\end{array}$ & 7500 & $\begin{array}{l}\text { Local } \\
\text { community }\end{array}$ \\
\hline
\end{tabular}

Primary Health Care Research \& Development 2012; 13: 289-293 


\section{Box 2 Overview of St. Andrea's Health Home}

St. Andrea's Health Home is in Empoli, one of the 11 municipalities of the 'Health Society of Empoli', which is being developed through six new 'Health Homes' commissioned at provincial level jointly with the municipality.

St. Andrea's opened in November 2008. It has 7500 registered patients and is open seven days a week, 24 hours a day. There are five GPs (all regional employees), four practice nurses, five administrators, one social worker and additional attached staff. Mental health is kept strictly separate. Nurses focus on prevention and are, as yet, barred from prescribing.

There are 14 other specialities working within St. Andrea's on a fee-for-service basis. In addition, St. Andrea's is the home for the Diabetes Association, a fitness gym, Alcoholics Anonymous and the Drugs Advisory Service, some local charities and the statutory social work function. Much has been achieved in a short space of time with, for instance, use of social care facilities rising by $63 \%$ from 2008 to 2009 .

Out-of-hours services are located within the Health Home and provided by Guardia Medica, an organisation covering 85000 people and involving local GPs on a rota basis.

devolved to primary care: St. Andrea's now provides specialist outpatient and inpatient services in 14 areas, including, for instance, cardiology, dermatology, gastroenterology and ophthalmology.

The shift from secondary to primary care accounted for cost savings in 2008 and 2009 of $6 \%$ and $22 \%$, respectively. Gain sharing is in place to encourage further change, with budget savings split in equal parts between the local health authority, physicians and St. Andrea's infrastructure account. The result appears to be a new mindset amongst primary care professionals in which demand pressures and claims for additional resources are no longer synonymous and where previously elusive
Box 3 Max Ivan Chercish Polyambulatoria; Bologna, Italy

The Max Ivan Chercish Polyambulatoria is a group general practice in the Emilia Romagna region. The region consists of 900000 people and is divided into six health districts for primary care provision and public health planning. These districts are known as Primary Care Groups (Nucleos delle Cure Primarie), each comprising geographic groupings of up to $20 \mathrm{GPs}$, 10 community nurses, three paediatricians, two physiotherapists, two social workers and 0.5 community pharmacists, as well as auxiliaries.

Established in 2000, the Max Ivan Chercish Polyambulatoria is open six days per week with a separate out-of-hours service agency on the ground floor. It has five GPs and a community pharmacist. Four consulting rooms accommodate a half-time cardiologist, dermatologist, orthodontist and ophthalmologist. There is a range of diagnostic, nursing and AHP services within the centre. Shared information is facilitated by electronic records.

Joint working is evident in the extended role of the community pharmacist who has a dispensing role and holds the doctors' prescribing budget. This financial relationship is welcomed by all team members as part and parcel of vertical integration.

changes in clinical behaviour appear possible. Such changes are facilitated through an employment contract between GPs and the local health authority. This contract outlines six objectives, each having specific targets. In 2010, all six objectives were met, meaning that the local authority met the rental costs for the building in which St. Andrea's is housed and GPs shared $€ 9000$ (c. £8000) in financial benefits.

At the regional level, the strategic commitment to extending primary care appears to have paid off with Tuscany reducing its complement of hospitals from 90 to 35 in 10 years.

In Bologna, similar shifts were reported with secondary care expenditure reduced to less than 
half of the regional budget and a future target of $43 \%$. At a local level, this shift appears to have been achieved by directly employing specialists from the four areas of highest secondary care demand (cardiology, orthodontics, ophthalmology and dermatology) within the Max Ivan group general practice. These specialists are integral to the primary care service - not part of a hospital outreach - and see/treat patients in the community or enable the GPs and practice nurses to do so. They have no inpatient beds. Their main purpose is diversion not prevention.

This change in the way services are provided has been achieved with limited use of pay-forperformance incentives. Instead, local administrators and political leaders appear to have successfully re-framed senior 'medical status' away from secondary care and towards communityoriented disciplines and settings.

\section{Facilitating 'localism'}

Political and financial federalism in Italy has allowed a compelling mix of decentralisation, local political structures and cultural engagement. This appears to have facilitated local decisionmaking, incorporating the views of patients/public, managers, clinicians and politicians. For instance, in Bologna, all proposals for increasing extended primary care are subject to local discussion with community representatives before being given the go ahead and paving the way for additional regional taxation and income. Moreover, in Tuscany, the St. Andrea's Health Home is named after a local saint in an attempt to reinforce local engagement. Participation is the watchword in both sites, with wide-ranging contributions to healthcare planning from elected councillors, cooperatives, voluntary groups, charities and the Church.

The ethos of decentralisation has permeated into a stewardship role for primary care with respect to community resources. Such stewardship is reinforced by locally elected mayors who are responsible for healthcare deficits and endorse local health targets in their manifesto. Critically, we were told that politicians are regarded by clinical leaders as inside the organisation'. For instance, provider groups in Bologna are commissioned in conjunction with Bologna's elected Presidentes who are responsible for municipal services. They link politically to the regional and provincial mayors who also have a role in drafting and approving the national Italian health strategy and its 'shared medical care' guidelines.

On the face of it having to account to so many stakeholders and their interests may seem an obstacle to reform. However, both sites reported real and sustained local engagement with local political buy-in, enabling hard decisions (eg regarding hospital closures). The national health plan provides a framework for regional and local approaches to strategic planning and delivery without curtailing the local political and managerial autonomy. Democratic elections at regional, provincial and municipality levels - all of which have an explicit role in planning services - facilitate engagement through planning mechanisms and the ballot box.

\section{Stable leadership}

With political leaders tending to move on every few years, system stability comes from the longterm positions occupied by clinical leaders. Public health doctors have occupied senior executive positions for over 20 years in each of the sites, ensuring a long-term steadying influence on strategic planning and change. The approach to clinical leadership is characterised by dialogue and an apparent political astuteness. This appears to foster 'professional organisations' that are characterised by the way in which they reach decisions: automatically sharing data and expertise, naturally interprofessional, working towards regional health plans but with a robust capacity to amend and expand these to meet local needs.

In both sites, stable leadership appears to filter positively into clinical integration 'on the ground'. The overarching emphasis on cooperation appears to set the tone for coordination of care with clinical networks - rather than financial incentives - the preferred means of achieving this.

\section{Discussion}

Our site visits were exploratory and present only a snapshot of extended primary care in Italy. However, the strategic focus on extended primary care in both Tuscany and Emilia Romagna appears to be achieving tangible results. Organisational reform focussed on extended primary care has 
been achieved by forging productive relationships across health and social care and across partisan political interests. Such relationships have provided legitimacy for reforms. Political and fiscal federalism have enabled citizens to contribute to effective decision-making and allowed clinicians, managers and politicians to trust them to do so. A deliberate reliance on senior clinicians and stable executive roles to implement service changes appears to have provided both impetus and sustainability.

Typically, primary care in Italy has not featured strongly in published primary care research. However, it appears that there is potential learning. Further review is needed to examine and endorse the substantial resource shift away from hospital-based care; to explore value for money, affordability and the cost effectiveness of extended primary care initiatives; and to understand if and how the partnerships underpinning extended primary care can operate effectively elsewhere (and particularly in the context of competitive, marketdriven systems and the continent-wide economic downturn, which has particularly affected Italy). Primary care researchers would therefore do well to turn their attention to Italy, build on this exploratory work and more systematically explore the effects of such programmes on specialty service utilisation and cost of care.

\section{Acknowledgements}

We thank Piero Salvadori and Gabriele Cavazza and all those in Bologna and Empoli who contributed to this work. This work was supported by The Nuffield Trust, an independent charity focussed on health policy and health services research, and the University of Winchester.

\section{References}

Atun, R. 2004: What are the advantages and disadvantages of restructuring a health care system to be more focused on primary care services? Copenhagen, Denmark: Health Evidence Network, WHO Regional Office for Europe.

Donatini, A., Rico, A., D’Ambrosio, M.G., Scalzo, A., Orzella, L., Cicchetti, A. and Profili, S. 2001: Italy: health systems review. Health Systems in Transition 3, 1-140.

Health Council of the Netherlands. 2004: European Primary Care (2004/20E). The Hague. Available at: http://www. gezondheidsraad.nl/en/publications/european-primary-care.

Maio, V. and Manzoli, L. 2002: The Italian health care system: W.H.O. ranking versus public perception. Pharmacy \& Therapeutics 27, 301-308.

Meads, G. 2009: The organisation of primary care in Europe: part 2 agenda - position paper of the European Forum for Primary Care. Quality in Primary Care 17, 225-34.

Saltman, R., Rico, A. and Boerma, W. (editors), 2006: Primary care in the driver's seat? Organisational reform in European primary care. Maidenhead: Open University Press.

Smith, J. and Ovenden, C. 2007: Developing integrated primary and community health services: what can we learn from the research evidence? Health Services Research Centre and School of Government, Victoria University of Wellington, New Zealand.

Stancati, M. 2010: Competitive care. Wall Street Journal 13 April 2010.

Wagner, E.H., Austin, B.T. and Von Korff, M. 1996: Organizing care for patients with chronic illness. Milbank Quarterly 74, 511-44. 